CENDEKIA, Vol. 12, No. 1, April 2018

p ISSN: 1978 2098; e ISSN: 2407 8557

Http://cendekia.pusatbahasa.or.id; Email: cendekiaoslo@gmail.com

Center of Language and Culture Studies, Surakarta, Indonesia

Arwan. 2018. Pengunaan Instruemn Asesmen Otentik dalam Pembelajaran

Membaca Kritis Teks Eksposisi pada Siswa SMK di BIMA

Cendekia, (2018), 12(1): 51 60. DOI: 10.30957/cendekia.v12i.436.

\title{
PENGGUNAAN INSTRUMEN ASESMEN OTENTIK DALAM PEMBELAJARAN MEMBACA KRITIS TEKS EKSPOSISI PADA SISWA SMK DI BIMA
}

\author{
Arwan \\ Magister Pendidikan Bahasa Indonesia \\ Universitas Mataram \\ Jl. Pemuda No. 35 Mataram 83125, Nusa Tenggara Barat \\ E-mail: daewan186@gmail.com
}

\begin{abstract}
This study aims to identify the authentic assessment forms used in learning critical reading of texts exposition. In this research, using qualitative methods with this kind of phenomenology. The results of this research is the description of the form of the process assessment and the results assessment are used in learning to read critically of exposition text. The process assessment in the form of a attitude journal to know the attitude of learners in learning. Indicators in this attitude journal included spiritual attitudes and social attitudes. the results assessment in the learning are used to determine the success of learners in understanding of exposition text. The assessment instrument made corresponding with $\mathrm{SK}, \mathrm{KD}$, and indicators of learning. The use of authentic assessment is impressive in learning to read critically is not implemented by all teachers. Understanding of learners tend to be determined globally.
\end{abstract}

Keywords: critical reading, text exposition, authentic.

\section{PENDAHULUAN}

Pembelajaran merupakan kegiatan yang bertujuan untuk merubah soft skills dan hard skills yang meliputi aspek kompetensi sikap, keterampilan, dan pengetahuan peserta didik. Ketiga aspek ini diharapkan mampu mempersiapkan peserta didik untuk memegang peran tertentu dalam kehidupan sosial. Pencapaian tujuan pembelajaran tersebut diperlukan peran guru secara fundamental. Oleh sebab itu, guru harus memperhatikan komponen-komponen dalam sistem pembelajaran. Komponen sistem pembelajaran dalam dunia pendidikan meliputi (1) tujuan, (2) isi/materi pelajaran, (3) strategi/metode pembelajaran, (4) alat dan sumber, dan (5) evaluasi pembelajaran. Kelima sistem pembelajaran ini merupakan komponen yang saling berkaitan sehingga guru dapat membimbing peserta didik dalam memahami dan memperoleh pengetahuan, memiliki keterampilan, dan sikap yang lebih baik.

Pada Kurikulum 2013 pembelajaran bahasa Indonesia berbasis teks, keterampilan soft skills dan hard skills diterapkan terhadap empat aspek keterampilan berbahasa, yakni (1) menyimak, (2) berbicara, (3) membaca, dan (4) menulis. Keempat keterampilan tersebut, membaca merupakan suatu hal yang sangat fundamental dalam 
CENDEKIA, Vol. 12, No. 1, April 2018

p ISSN: 1978 2098; e ISSN: 2407 8557

Http://cendekia.pusatbahasa.or.id; Email: cendekiaoslo@gmail.com

Center of Language and Culture Studies, Surakarta, Indonesia

Arwan. 2018. Pengunaan Instruemn Asesmen Otentik dalam Pembelajaran

Membaca Kritis Teks Eksposisi pada Siswa SMK di BIMA

Cendekia, (2018), 12(1): 51 60. DOI: 10.30957/cendekia.v12i.436.

proses belajar dan pembentukan intelektual. Kualitas hidup manusia dapat dilihat dari bagaimana manusia dapat memaksimalkan potensi dirinya. Salah satu upaya untuk dapat memaksimalkan potensi diri adalah dengan membaca. Oleh sebab itu, pembelajaran membaca perlu dilakukan dengan saksama sehingga peserta didik mampu menguak cakrawala pengetahuan.

Keterampilan membaca memiliki berbagai jenis, yaitu (1) membaca berdasarkan keras/lemahnya suara, (2) membaca berdasarkan tingkat kontrol pendidik, (3) membaca berdasarkan kecepatan waktu, dan (4) membaca berdasarkan tingkatan belajar. Membaca berdasarkan tingkat kontrol pendidik/guru merupakan kegiatan yang dilakukan dengan adanya kontrol dari guru terhadap kegiatan dalam memperoleh informasi. Ada dua kategori dalam membaca berdasarkan tingkat kontrol pendidik, yakni membaca intensif dan ekstensif.

Pertama, membaca ekstensif merupakan kegiatan membaca untuk menumbuhkan kesukaan terhadap membaca. Hal ini sepadan dengan Grellet (dalam Ghazali, 2010:207) yang menyatakan bahwa membaca ekstensif merupakan membaca teks-teks panjang untuk tujuan rekreasi (bersenang-senang) dan untuk menambah pengetahuan umum atau meningkatkan kelancaran dalam berbahasa. Kedua, membaca intensif merupakan kegiatan memperoleh informasi dari beragam teks secara cermat untuk memahami, menilai, merefleksikan dalam rangka pemahaman kekritisan dan kreativitas peserta didik. Dalam hal ini membaca kritis merupakan suatu keterampilan yang memerlukan kontrol guru terhadap proses pemahaman peserta didik. Hal ini sepadan dengan pendapat Harmer (2007:284) yang menyatakan bahwa membaca intensif merupakan proses memahami isi bacaan secara keseluruhan dan mendalam, sehingga dapat memperoleh pesan yang ingin disampainan penulis. Oleh karena itu, membaca kritis adalah proses membaca yang tidak hanya menuntut pembaca untuk memahami isi bacaan. Akan tetapi, pembaca harus mampu menilai bacaan yang dikombinasikan dengan skemata pembaca.

Kemampuan membaca kritis dapat dipelajari melalui salah satu pembelajaran yang sesuai dengan Kompetensi Dasar 3.3 menganalisis isi (permasalahan, argumentasi, pengetahuan, dan rekomendasi), struktur, dan kebahasaan teks eksposisi yang didengar dan atau dibaca. Teks eksposisi merupakan suatu teks yang memuat informasi fakta yang disertai pendapat penulis sehingga dapat menghasilkan sikap para pembaca untuk menerima atau menolak informasi sesuai dengan keinginan penulis. Informasi berkaitan dengan aktifitas dan kebutuhan manusia dalam kehidupan.

Pada setiap keterampilan berbahasa di atas, diperlukan proses evaluasi yang tepat. Evaluasi memiliki peran penting untuk mengetahui tingkat keberhasilan peserta didik dalam pembelajaran secara impresif. Menurut Subali (2014), evaluasi adalah proses penetapan suatu program yaitu apakah suatu program terencana dengan sempurna, terlaksana dengan baik, tercapai dengan sempurna, dan berdampak sangat luas. Evaluasi program pembelajaran dalam arti luas berupa penetapan apakah kurikulum (termasuk silabus dan rencana pelaksanaan pembelajaran/RPP) sudah tersusun dengan sempurna, apakah proses pembelajaran sudah sesuai dengan rencana, apakah hasil yang dicapai peserta didik sebagai peserta program sudah sesuai dengan 
CENDEKIA, Vol. 12, No. 1, April 2018

p ISSN: 1978 2098; e ISSN: 2407 8557

Http://cendekia.pusatbahasa.or.id; Email: cendekiaoslo@gmail.com

Center of Language and Culture Studies, Surakarta, Indonesia

Arwan. 2018. Pengunaan Instruemn Asesmen Otentik dalam Pembelajaran

Membaca Kritis Teks Eksposisi pada Siswa SMK di BIMA

Cendekia, (2018), 12(1): 51 60. DOI: 10.30957/cendekia.v12i.436.

harapan, apakah setelah peserta didik bekerja dapat menunjukkan kinerja (performans) yang profesional, apakah aspek pendukung program, termasuk sarana-prasarana, SDM, dan lingkungan tempat penyelenggaraan pendidikan sudah sesuai harapan.

Kegiatan mengevaluasi harus mampu memotret kemampuan peserta didik secara autentik. Oleh karena itu, penggunaan asesmen autentik sangat diperlukan dalam pembelajaran Kurikulum 2013. Hal ini sepadan dengan pendapat Marhaeni \& Artini (2015:500) yang menyatakan bahwa penggunaan asesmen otentik sekarang ini sudah menjadi keharusan, mengingat pilar pendidikan yang digaungkan oleh UNESCO bukan hanya belajar untuk mengetahui (learning to know) melainkan juga untuk terampil menggunakan apa yang dipelajari (learning to do); mencapai aktualisasi diri di dunia nyata (learning to be) dan mampu menjadi bagian masyarakat yang harmonis (learning to live together).

Asesmen autentik adalah rangkaian penilaian yang dilakukan secara nyata untuk menilai proses maupun hasil akhir suatu kompetensi dasar dalam pembelajaran. Penilaian bukan hanya dari satu sisi, namun dengan melibatkan berbagai bentuk penilaian yang mencerminkan pembelajaran, misalnya, prestasi siswa, motivasi, dan sikap. Penggunaan asesmen autentik mendorong siswa untuk menggunakan pengetahuan ilmiah pada konteks riil bukan membuat/menyusun sesuatu yang baru dan tidak dikenal siswa. Teknik penilaian otentik, misalnya (1) kinerja penilaian, (2) portofolio, dan (3) penilaian diri (O’Malley dan Pierce, 1996:4; Yusuf, 2015:292-294; Basuki \& Hariyanto, 2015:168; Nurgiyantoro, 2011:23; Anggreadi, 2015:76; dan Suardita, 2014:5).

Pembelajaran membaca yang dilakukan selama ini masih belum melibatkan penggunaan penilaian otentik. Penilaian lebih banyak dilakukan setelah akhir pembelajaran membaca dan biasanya hanya dilakukan dengan cara menyajikan sejumlah pertanyaan isi bacaan yang harus diisi siswa. Proses pembelajaran semacam ini dalam pandangan penulis kurang mampu mengukur secara utuh kemampuan membaca siswa, kurang dapat mengembangkan kemampuan membaca, dan tidak berdampak terhadap pengembangan karakter siswa (Abidin, 2012).

Berdasarkan paparan tersebut, penelitian ini bertujuan untuk mengidentifikasi penggunaan perangkat instrumen asesmen autentik dalam pembelajaran membaca kritis di Sekolah Menengah Kejuruan (SMKN 1 Bima).

\section{METODE}

Penelitian ini menggunakan metode deskriptif kualitatif. Jenis metode kualitatif yang digunakan, yaitu fenomenologi. Istilah fenomenologi secara etimologis berasal dari kata fenomena dan logos. Fenomena berasal dari kata kerja Yunani "phainesthai"yang berarti menampak, dan terbentuk dari akar kata fantasi, fantom, dan fosfor yang artinya sinar atau cahaya. Dari kata itu terbentuk kata kerja, tampak, terlihat karena bercahaya. Donny (2005:150), menuliskan fenomenologi adalah ilmu tentang esensi-esensi kesadaran dan esensi ideal dari obyek-obyek sebagai korelasi dengan kesadaran. 
CENDEKIA, Vol. 12, No. 1, April 2018

p ISSN: 1978 2098; e ISSN: 2407 8557

Http://cendekia.pusatbahasa.or.id; Email: cendekiaoslo@gmail.com

Center of Language and Culture Studies, Surakarta, Indonesia

Arwan. 2018. Pengunaan Instruemn Asesmen Otentik dalam Pembelajaran

Membaca Kritis Teks Eksposisi pada Siswa SMK di BIMA

Cendekia, (2018), 12(1): 51 60. DOI: 10.30957/cendekia.v12i.436.

Menurut Moleong (2007:8), ada tiga ciri pokok fenomenologis yang dilakukan oleh peneliti fenomenologis, yaitu (1) mengacu kepada kenyataan, dalam hal ini kesadaran tentang sesuatu benda secara jelas, (2) memahami arti peristiwa dan kaitankaitannya terhadap orang-orang yang berada dalam situasi-situasi tertentu, dan (3) memulai dengan diam. Dalam penelitian ini, peneliti memposisikan diri sebagai pengamat yang akan memotret penggunaan instrumen asesmen dalam pembelajaran membaca kritis. Pembelajaran yang akan diamati berkaitan dengan teks eksposisi.

Subjek penelitian ini adalah guru bahasa Indonesia kelas X di SMKN 1 Bima. Ada tiga alasan pemilihan sekolah ini sebagai tempat penelitian, yakni (1) berdasarkan kriteria, sekolah ini sudah menerapkan Kurikulum 2013, (2) telah dilakukan observasi untuk analisis kebutuhan, dan (3) peneliti telah memiliki pengetahuan awal terhadap guru dan peserta didik. Ketiga alasan tersebut dapat memudahkan peneliti dalam pemotretan penggunaan asesmen.

Data yang diperoleh dari penelitian ini adalah data berupa penggunaan asesmen autentik membaca kritis. Data tersebut diperoleh dengan menggunakan empat instrumen, yaitu (1) pedoman wawancara, (2) pedoman studi dokumen, (3) lembar observasi, dan (4) angket. Proses wawancara dilakukan secara terstruktur kepada guru berkaitan dengan penggunaan instrumen penilaian. Dokumentasi dilakukan dengan mengumpulkan data berupa asesmen pembelajaran dan pedoman penggunaan instrumen asesmen. Observasi adalah metode pengumpulan data yang menggunakan pengamatan langsung terhadap obyek penelitian. Angket berisi pertanyaan mengenai pengetahuan, penggunaan, dan kebutuhan.

Analisis data dalam penelitian ini dilakukan dengan tiga alur kegiatan pokok, yakni (1) reduksi data merupakan proses pemilihan, pemusatan perhatian, penyederhanaan, abstraksi, dan transformasi data "kasar" yang muncul dari catatan lapangan. Reduksi data berlangsung terus-menerus selama proses penelitian, (2) penyajian data yang tersusun secara sistematis, dan (3) penarikan kesimpulan yang dilakukan dengan merumuskan tindak pemahaman sederhana, tindak afirmasi dan negasi. Reduksi data merupakan proses pemilihan, pemusatan perhatian, penyederhanaan, abstraksi, dan transformasi data "kasar" yang muncul dari catatan lapangan.

\section{HASIL}

Hasil penelitian ini menjabarkan dua aspek yang berkaitan dengan bentuk asesmen autentik yang digunakan dalam pembelajaran membaca kritis teks eksposisi pada siswa kelas X SMKN 1 Bima. Bentuk asesmen dalam pembelajaran membaca kritis, yakni (1) asesmen proses, dan (2) asesmen hasil akhir. Kedua hasil penelitian di atas diperoleh dari observasi, wawancara, angket, dan dokumentasi yang dilakukan pada guru kelas X SMKN 1 Bima. Penilaian proses dan hasil digunakan oleh guru untuk mengetahui pemahaman dan sikap peserta didik dalam pembelajaran membaca kritis. Paparan selengkapnya disajikan sebagai berikut ini. 
CENDEKIA, Vol. 12, No. 1, April 2018

p ISSN: 1978 2098; e ISSN: 2407 8557

Http://cendekia.pusatbahasa.or.id; Email: cendekiaoslo@gmail.com

Center of Language and Culture Studies, Surakarta, Indonesia

Arwan. 2018. Pengunaan Instruemn Asesmen Otentik dalam Pembelajaran

Membaca Kritis Teks Eksposisi pada Siswa SMK di BIMA

Cendekia, (2018), 12(1): 51 60. DOI: 10.30957/cendekia.v12i.436.

\section{Penggunaan asesmen proses}

Asesmen proses yang digunakan untuk mengetahui sikap peserta didik selama pembelajaran. Asesmen proses dilakukan sebelum kegiatan inti dan saat pelaksanaan kegiatan inti. Pada kegiatan pembukaan (sebelum kegiatan inti), penilaian proses dilakukan terhadap persiapan peserta didik dalam menerima pembelajaran, sedangkan pada pelaksanaan kegiatan inti asesmen proses dilakukan untuk melihat sikap peserta didik dalam menerima materi pembelajaran. Kemudian, hasil asesmen proses ini dituangkan dalam pada kegiatan akhir pembelajaran atau setelah pembelajaran selesai. Asesmen proses yang telah dievaluasi dituangkan dalam jurnal sikap. Hal ini sesuai hasil pengamatan dan wawancara yang dilakukan terhadap guru SMK kelas X. Jurnal sikap dan penilaian sikap yang dibuat oleh guru dalam Rancangan Pelaksanaan Pembelajaran (RPP), sebagai berikut.

Tabel 1. Jurnal sikap

\begin{tabular}{|c|c|c|l|c|}
\hline No & Tanggal & Nama Siswa & \multicolumn{1}{|c|}{ Catata Prilaku } & $\begin{array}{c}\text { Butir } \\
\text { Sikap }\end{array}$ \\
\hline 1 & $13-11-2017$ & Syaifullah & $\begin{array}{l}\text { Berani berpendapat, } \\
\text { bertanya, atau menjawab } \\
\text { pertanyaan. }\end{array}$ & \\
\hline dst. & & & & Kode: SR2 \\
\hline \multicolumn{3}{|c|}{} \\
\hline
\end{tabular}

Tabel 2. Penilaian sikap

\begin{tabular}{|c|l|c|c|c|c|c|c|}
\hline No & Nama Siswa & $\begin{array}{c}\text { Jujur } \\
\mathbf{( 4 , 3 , 2 , 1 )}\end{array}$ & $\begin{array}{c}\text { Peduli } \\
\mathbf{( 4 , 3 , 2 , 1 )}\end{array}$ & $\begin{array}{c}\text { Santun } \\
\mathbf{( 4 , 3 , 2 , 1 )}\end{array}$ & $\begin{array}{c}\text { Disiplin } \\
\mathbf{( 4 , 3 , 2 , 1 )}\end{array}$ & $\begin{array}{c}\text { Tanggun } \\
\text { g jawab } \\
\mathbf{( 4 , 3 , 2 , 1 )}\end{array}$ & $\begin{array}{c}\text { Rata- } \\
\text { rata }\end{array}$ \\
\hline 1 & Syaifullah & 3 & 2 & 2 & 3 & 4 & \\
\hline 2 & Abubakar & & & & & & \\
\hline dst. & \multicolumn{2}{|r|}{} & & & & \multicolumn{3}{c|}{ Kode: NR4 } \\
\hline
\end{tabular}

Berikut ini, bentuk instrumen penilaian untuk mengetahuai sikap peserta didik dalam tabel jurnal sikap yang telah dirancang oleh guru kelas X SMK. Instrumen penilaian sikap diperoleh dari Rancangan Pelaksanaan Pembelajaran (RPP) yang dibuat oleh guru. Akan tetapi, tidak semua guru menggunakan asesmen proses sesuai dengan yang telah dirancang sebelumnya. Hal ini disebabkan oleh beberapa faktor. Pertama, guru telah mengenal peserta didik sehingga dapat mengingat peserta didik yang terbiasa bersikap aktif dan tidak aktif. Kedua, guru merasa peserta didik tidak mampu berpikir secra kritis. Ketiga, sebagian guru cenderung melakukan penilaian sikap secara global. Instruemn sikap disajian pada tabel 3. 
CENDEKIA, Vol. 12, No. 1, April 2018

p ISSN: 1978 2098; e ISSN: 2407 8557

Http://cendekia.pusatbahasa.or.id; Email: cendekiaoslo@gmail.com

Center of Language and Culture Studies, Surakarta, Indonesia

Arwan. 2018. Pengunaan Instruemn Asesmen Otentik dalam Pembelajaran

Membaca Kritis Teks Eksposisi pada Siswa SMK di BIMA

Cendekia, (2018), 12(1): 51 60. DOI: 10.30957/cendekia.v12i.436.

Tabel 3. Instrumen sikap

\begin{tabular}{|c|c|}
\hline Sikap & Indikator \\
\hline $\begin{array}{l}\text { 1. } \\
\text { Sikap spiritual }\end{array}$ & \multirow[b]{2}{*}{$\begin{array}{l}\text { • } \\
\text { Berdoa sebelum dan sesudah menjalankan } \\
\text { kegiatan } \\
\text { • } \\
\text { Bersyukur atas nikmat dan karunia Tuhan } \\
\text { Yang Maha Esa } \\
\text { • } \\
\text { Menjalani ibadah tiap waktu } \\
\text { • } \\
\text { Mengucapkan syukur ketika berhassil } \\
\text { mengerjakan sesuatu } \\
\text { • } \\
\text { Berserah diri (tawakal) kepada tuhan setelah } \\
\text { berikhtiar atau melakukan usaha. } \\
\text { - } \\
\text { Memelihara hubungan baik dengan sesama } \\
\text { umat ciptaan Tuhan Yang Maha Esa } \\
\bullet \\
\text { Menghormati orang lain mejalankan ibadah } \\
\text { sesuai dengan agamanya. }\end{array}$} \\
\hline $\begin{array}{l}\text { Menghargai dan menghayati ajaran } \\
\text { agama yang dianut. }\end{array}$ & \\
\hline $\begin{array}{l}2 . \\
\text { Sikap sosial }\end{array}$ & $\begin{array}{l}\text { - } \\
\text { Berpendapat atau melaukan kegiatan tanpa } \\
\text { ragu-ragu } \\
\bullet \\
\text { Mampu membuat keputusan dengan cepat } \\
\bullet \\
\text { Tidak mudah putus asa } \\
\bullet \\
\text { Tidak canggung dalam bertindak } \\
\bullet \\
\text { Berani berpendapat, bertanya, atau menjawab } \\
\text { pertanyaan. }\end{array}$ \\
\hline
\end{tabular}

\section{Penggunaan asesmen hasil}

Asesmen hasil digunakan untuk mengetahui pemahaman peserta didik terhadap pembelajaran yang dilakukan. Dalam hal ini, peserta didik diberi instrumen penilaian berupa tes yang sesuai dengan indikator pembelajaran. tes dilakukan setelah peserta 
CENDEKIA, Vol. 12, No. 1, April 2018

p ISSN: 1978 2098; e ISSN: 2407 8557

Http://cendekia.pusatbahasa.or.id; Email: cendekiaoslo@gmail.com

Center of Language and Culture Studies, Surakarta, Indonesia

Arwan. 2018. Pengunaan Instruemn Asesmen Otentik dalam Pembelajaran

Membaca Kritis Teks Eksposisi pada Siswa SMK di BIMA

Cendekia, (2018), 12(1): 51 60. DOI: 10.30957/cendekia.v12i.436.

didik membaca teks eksposisi dan mendapat penjelasan dari guru. Bentuk tes yang digunakan dalam pembelajaran membaca kritis teks eksposisi, seperti dalam tabel 4.

Tabel 4. Bentuk tes dalam membaca kritis

1. Sebutkan dan jelaskan struktur teks eksposisi!

2. Sebutkan dan jelaskan ciri kebahasaan teks eksposisi!

3. Identifikasilah ciri-ciri teks eksposisi di atas!

4. Bedahlah teks tersebut berdasarkan strukturnya!

5. Buatlah teks eksposisi dengan tema yang sudah ditentukan!

Kode: NR1

Berdasarkan tes yang digunakan di atas, penilaian hasil dilakukan dengan mengisi rubrik penilaian pengetahuan peserta didik. Penilaian pengetahuan peserta didik dilakukan untuk mengukur keberhasilan dalam pembelajaran. Akan tetapi, tidak semua guru melakukan asesmen untuk mengetahui pemahaman peserta didik secara langsung sesuai dengan RPP yang telah dirancang. Hal ini disebabkan oleh beberapa faktor baik berasal dari individu guru maupun pemerintah. Pertama, tidak adanya bahan ajar yang dapat dijadikan pedoman dalam pembelajaran sesuai Kurikulum 2013 revisi. Oleh sebab itu, asesmen yang telah dirancang sebelumnya dibuat sebagai syarat dari pemerintah. Kedua, peserta didik tidak mampu membaca secara kritis sehingga sulit untuk dilakukan asesmen dan asesmen dilakukan secara global. Bentuk penilaian terhadap pengetahuan peserta didik dapat dilihat pada Tabel 5.

Tabel 5.Penilaian pengetahuan siswa

\begin{tabular}{|c|l|l|r|r|r|r|}
\hline No & Nama Siswa & \multicolumn{1}{|c|}{$\begin{array}{c}\text { Aspek (sesuai } \\
\text { Kompetensi Dasar) }\end{array}$} & \multicolumn{3}{|c|}{ Kriteria } \\
\cline { 3 - 7 } & & $\begin{array}{c}\text { Sangat } \\
\text { baik }\end{array}$ & Baik & Cukup & Kurang \\
\hline 1 & Syaifullah & $\begin{array}{l}\text { Memahami isi } \\
\text { Memahami struktur } \\
\text { Memahami ciri } \\
\text { kebahasaan }\end{array}$ & $\sqrt{ }$ & $\sqrt{ }$ & & \\
\hline 2 & Abubakar & $\begin{array}{l}\text { Memahami isi } \\
\text { Memahami struktur } \\
\text { Memahami ciri } \\
\text { kebahasaan }\end{array}$ & $\sqrt{ }$ & $\sqrt{ }$ & $\sqrt{ }$ & \\
\hline & \multicolumn{3}{|l|}{ Kode: NR3 } \\
\hline
\end{tabular}

Berdasarkan hasil angket dan observasi yang dilakukan peneliti, pembelajaran membeca teks eksposisi tidak menggunakan asesmen autentik dengan berbagai bentuk penilaian. Guru hanya menggunakan bentuk asesmen proses dan asesmen pengetahuan. Penilaaian proses yang dilakukan pada penilaian sikap bukan pada proses pemahaman peserta didik terhadap pembelajaran. Akan tetapi, guru telah memahami bentuk-bentuk 
CENDEKIA, Vol. 12, No. 1, April 2018

p ISSN: 1978 2098; e ISSN: 2407 8557

Http://cendekia.pusatbahasa.or.id; Email: cendekiaoslo@gmail.com

Center of Language and Culture Studies, Surakarta, Indonesia

Arwan. 2018. Pengunaan Instruemn Asesmen Otentik dalam Pembelajaran

Membaca Kritis Teks Eksposisi pada Siswa SMK di BIMA

Cendekia, (2018), 12(1): 51 60. DOI: 10.30957/cendekia.v12i.436.

asesmen autentik. Berikut ini hasil angket yang telah diisi guru berkaitan dengan pemahaman guru terhadap asesmen autentik seperti dalam Tabel 6.

Tabel 6. Jenis assessmen otentik.

Jenis penilaian autentik yang biasa digunakan dalam pembelajaran membaca kritis, yakni (a) tes objektif, (b) tes non-objektif, (c) partofolio, (d) produk, (e) penilaian sejawat, dan (f) penilaian diri.

Kode: SW2

\section{BAHASAN}

Pembahasan sesuai dengan hasil penelitian ini memaparkan dua fenomena yang terjadi di lapangan (sekolah) khususnya SMKN 1 Bima. Kedua pembahasan tersebut berkaitan dengan penggunaan instrumen asesmen dalam pembelajaran membaca kritis. Asesmen merupakan proses mendokumentasikan pengetahuan, keterampilan, dan sikap peserta didik untuk memperoleh informasi yang berkitan dengan pemahaman dan apa yang dilakukan/dikerjakan oleh peserta didik dalam pembelajaran di sekolah.

Alat penilaian yang digunakan guru, yaitu tes dan nontes. Tes dilakukan untuk mengetahui pemahaman peserta didik terhadap pembelajaran membaca teks eksposisi, sedangkan nontes digunakan untuk mengukur sikap peserta didik pada kegiatan awal berkaitan dengan kesiapan peserta didik dalam pembelajaran, kegiatan inti, dan kegiatan akhir pembelajaran. Oleh karena itu, sesuai denga hasil penelitian yang telah dilakukan oleh peneliti, asesmen yang digunakan dalam pembelajaran membaca kritis, yakni (1) asesmen proses, dan (2) asesmen hasil. Kedua hasil penelitian di atas diperoleh dari observasi, wawancara, angket, dan dokumentasi yang dilakukan di kelas X SMKN 1 Bima. Penilaian proses dan hasil dilakukan oleh guru untuk mengetahui pemahaman dan sikap peserta didik dalam pembelajaran membaca kritis. Paparan selengkapnya disajikan sebagai berikut.

Asesmen proses yang digunakan oleh guru untuk mengetahui sikap peserta didik selama pembelajaran. Asesmen proses dilakukan sebelum kegiatan inti dan saat pelaksanaan kegiatan inti. Pada kegiatan pembukaan, penilaian proses dilakukan terhadap persiapan peserta didik dalam menerima pembelajaran, sedangkan pada pelaksanaan kegiatan inti asesmen proses dilakukan untuk melihat sikap peserta didik dalam menerima materi pembelajaran. Asesmen hasil digunakan oleh guru untuk mengetahui pemahaman peserta didik terhadap pembelajaran yang telah dilakukan. Dalam hal ini, peserta didik diberi instrumen penilaian yang sesuai dengan indikator yang ingin dicapai dalam pembelajaran.

Asesmen proses tidak dilakukan terhadap proses pemahaman peserta didik dalam membaca dan memahami teks eksposisi. Padahal, asesmen yang baik dan mampu memotret pemehaman peserta didik dilakukan pada proses dan hasil dalam pembelajaran membaca kritis. Hal ini sepadan dengan pendapat Wahyuni dan Ibrahim (2014:2) yang menyatakan bahwa asesmen adalah proses pengumpulan informasi 
CENDEKIA, Vol. 12, No. 1, April 2018

p ISSN: 1978 2098; e ISSN: 2407 8557

Http://cendekia.pusatbahasa.or.id; Email: cendekiaoslo@gmail.com

Center of Language and Culture Studies, Surakarta, Indonesia

Arwan. 2018. Pengunaan Instruemn Asesmen Otentik dalam Pembelajaran

Membaca Kritis Teks Eksposisi pada Siswa SMK di BIMA

Cendekia, (2018), 12(1): 51 60. DOI: 10.30957/cendekia.v12i.436.

tentang peserta didik berkenaan dengan yang mereka ketahui dan yang mereka lakukan. Instrumen asesmen yang dilakukan tidak hanya untuk menilai hasil akhir dalam pembelajaran. Akan tetapi, memperhatikan bagaimana proses pembelajaran itu berlangsung itu dilakukan oleh siswa.

Serupa dengan itu, menurut Yusuf (2015:14), asesmen merupakan suatu proses pengumpulan data dan/atau informasi (termasuk da dalamnya pengolahan dan pendokumentasian) secara sistematis tentang suatu atribut, orang atau objek, baik berupa data data kualitatif maupun data kuantitatif tentang jumlah, keadaan, kemampuan atau kemajuan suatu atribut, objek atau orang/individu yang dinilai, tanpa merujuk pada keputusan nilai. Berdasarkan kedua pendapat di atas, asesmen proses dan asesmen hasil perlu dilakukan untuk memotret pemahaman peserta didik. Dalam hal ini bagaimana proses memperoleh pemahaman yang dialami oleh peserta didik sehingga menghasilkan suatu sikap yang positif dan keterampilan sesuai dengan indikator yang ingin dicapai. Oleh karena itu, asesmen yang digunakan oleh guru dalam pembelajaran membaca kritis masih harus diperhatikan sehngga tidak adanya kecendrungan menentukan pemahaman peserta didik secara global.

\section{SIMPULAN}

Asesmen pembelajaran membaca kritis yang digunakan oleh guru ada dua, yakni asesmen proses dan asesmen hasil. Kedua asesmen digunakan untuk mengukur dan menilai aspek yang berbeda. Asesmen proses berupa jurnal sikap digunakan untuk mengetahui sikap peserta didik dalam pembelajaran membaca kritis. Akan tetapi, asesmen hasil digunakan untuk mengetahui keberhasilan peserta didik dalam memahami teks eksposisi yang telah dibaca. Instrumen asesmen hasil berpedoman pada SK, KD, dan Indikator pembelajaran. Akan tetapi, asesmen autentik belum digunakan secara menyeluruh oleh guru yang mengajar di Sekolah Menengah Kejuruan (SMK). Kecendrungan menentukan pemahaman peserta didik secara global masih dilakukan oleh beberapa guru.

\section{DAFTAR PUSTAKA}

Anderson, M dan Anderson K. 1997. Text types: In English 2. South Yarra: Macmillan Education Australia.

Harsiati, T. 2011. Penilaian dalam Pembelajaran (Aplikasi pada pembelajaran

Membaca dan Menulis). Malang: UM Press.

Harmer, J. 2007. The Practice of English Language Teaching. New York: Pearson

Longman.

Nurhadi. 2010. Membaca Cepat dan Efektif. Malang: fakultas Sastra Universitas Negeri Malang. 
CENDEKIA, Vol. 12, No. 1, April 2018

p ISSN: 1978 2098; e ISSN: 2407 8557

Http://cendekia.pusatbahasa.or.id; Email: cendekiaoslo@gmail.com

Center of Language and Culture Studies, Surakarta, Indonesia

Arwan. 2018. Pengunaan Instruemn Asesmen Otentik dalam Pembelajaran

Membaca Kritis Teks Eksposisi pada Siswa SMK di BIMA

Cendekia, (2018), 12(1): 51 60. DOI: 10.30957/cendekia.v12i.436.

Oktavia, T. 2015. Peningkatan Keterampilan Menulis Teks Eksposisi melalui Model Investigasi Kelompok dengan Media Berita dalam Surat Kabar pada Siswa Kelas X-4 TKJ SMK NU Ungaran Kabupaten Semarang (Skripsi). Semarang: Universitas Negeri Semarang.

O’Malley, J.M. dan Pierce, L.V. 1996. Authentic Assessment for English Language Leaners (Practical Approaches for teachers). San Fracisco: Longman.

Priyatni, E. T dan Harsiati, T. 2013. Bahasa dan Sastra Indonesia SMA/MA Kelas X. Jakarta: Bumi Aksara.

Tarigan, H.G. 2008. Membaca: Sebagai Suatu Keterampilan Berbahasa. Bandung: Percetakan Angkasa. 